\title{
Awareness and Compliance of COVID-19 Imaging and Guidelines among Radiology Staff
}

\section{Mohamed Hasaneen $^{1 *}$ and Mustafa Alhasan ${ }^{1,2}$}

${ }^{1}$ Radiography and Medical Imaging Department, Fatima College of Health Sciences, $U A E$

${ }^{2}$ Radiologic Technology Program, Applied Medical Sciences College, Jordan University of Science and Technology, Jordan

*Corresponding Author: Mohamed Hasaneen, Radiography and Medical Imaging Department, Fatima College of Health Sciences, UAE.
Received: August 13, 2021

Published: September 20, 2021

(C) All rights are reserved by Mohamed

Hasaneen and Mustafa Alhasan.

\begin{abstract}
Introduction: lack of knowledge and understanding of COVID-19 disease among radiology staff may result in rapid spread of the infection among them due to the screening of COVID-19 patients using Chest x-ray and Chest CT scan to diagnose the disease. Accordingly, the purpose of this cross-sectional study is to evaluate the level of awareness and compliance of COVID-19 imaging and guidelines among the radiology staff.

Methods: Across-sectional study was conducted among the radiology staff between September and November 2020. An online questionnaire was developed and shared with the participants from different regions. The questionnaire emphasized on COVID-19 Awareness, infection control procedures and the role of imaging for COVID-19 diagnosis.

Results: A total of 262 radiology staff agreed to participate in this study. $48 \%$ of the respondents were females. The average age was 36 years. The majority (71\%) were bachelor holders. Among the participants, $91 \%$ were radiographers while $9 \%$ were radiologists. Regarding COVID-19 imaging section, the mean score (62\%) was significantly higher for the Radiologists $(\mathrm{P}<0.05)$. Regarding the health infection control questions, most of the respondents reported Sometimes to Always on the Likert scale (1-5) for applying the safety procedures. The job title, work experience and the location factors significantly predicted the COVID-19 imaging awareness scores $(\mathrm{p}<0.05$. $)$.

Discussion: Awareness and compliance of COVID-19 imaging and infection control guidelines are important issues for the radiology staff to ensure their own safety and the efficient delivery of patient imaging procedures.

Conclusion: The radiology staff demonstrated an acceptable overall COVID-19 awareness level. The compliance with the infection control guidelines is above average. However, more COVID-19 imaging sessions are recommended to improve the overall performance.
\end{abstract}

Keywords: Awareness; Compliance; COVID-19; Imaging; Radiology; Guidelines

\section{Introduction}

Coronavirus (COVID-19) is a life-threatening disease of the respiratory system caused by an enveloped single-strand ribonucleic acid novel coronavirus that belongs to the Coronaviridae family, and was first discovered in December 2019 in Wuhan, China. Hence, the name is Coronavirus disease 2019. Moreover, Corona- viridae family consist of Six types of coronavirus that cause human disease; four types merely associate with mild respiratory indications, while the other two, namely, Middle East respiratory syndrome (MERS) coronavirus and severe acute respiratory syndrome (SARS) coronavirus have caused epidemics with high mortality rates. Thus, COVID-19 also named SARS-CoV-2. It is considered a dangerous disease because of the large percentage of asymptom- 
atic and pre-symptomatic infected persons. Also, since COVID-19 is a respiratory virus caused by a strain of coronavirus SARS-CoV-2, current evidences suggests that the virus COVID-19 is transmitted from person to person through close contact and respiratory droplet transmission when a person coughs or sneezes [1,2]. However, the disease is contagious and infectious, with clinical symptoms varies from person to person. The symptoms include fever, dry cough, fatigue, dyspnea and pneumonia [3].

Reverse - Transcription Polymerase Chain Reaction (RT-PCR) is a pharyngeal swab and considered a standard diagnostic test for confirming novel COVID-19 infection. A PCR test was conducted at the beginning of the pandemic but due to frequent delay in the result, the doctors soon realized the importance of medical imaging as a diagnostic tool for screening of COVID-19. Imaging plays a vital role in diagnosis of the suspected infectious disease, and helped in treatment and evaluation of confirmed cases. Medical imaging has further aided the doctors in diagnosing the progression of the COVID-19 infection. Moreover, the radiologist should be aware of the recent manifestation and variances of the novel COVID-19 infection. Chest Radiography (CXR) can be used with triaging patients, as with mild cases of COVID-19 CXR can be insensitive. However, the general x-rays are mainly used to monitor the radiographically detectable pneumonia. Multiple and diverse imaging features of the COVID-19 have been observed in different modalities, however, the appearance of GGO (Ground Glass Opacity) may not be visible in general chest X-rays and thus could lead to false negative findings. Recent studies have shown widely the use of chest CT to assess COVID-19 patients [4-6].

Ultrasound was unlikely to be used in the diagnosis of COVID-19 infection, as lung ultrasound was insufficient to support the presence of infection in the lungs at early and mild stages. Furthermore, there was a risk of operator to be infected with the virus when being in close contact with the COVID-19 patient [4].

Few studies have been conducted on the role of MRI during COVID-19 findings. MRI report of a positive PCR patients has shown presence of lesion in the liver, but many details revealed when a contrast study was conducted. Additionally, the MRI has revealed bilateral multi lobular focal lung infiltrations [7].

While COVID-19 has been disseminating worldwide, hospitals in many countries where trying to deal with this serious pandemic as it has affected many healthcare providers and led to many deaths. Medical Imaging Department personnel, particularly the radiographers, are working on the frontline and are expected to be in a close contact with COVID-19 patients during the outbreak. They are responsible of preventing and controlling infection and radiation to both patients and medics prior to commencing any examination. The transmission of the virus to radiology staff can be diminished by an optimal infection control implemented within the department. The principal and the most important step of preventing the spread is decontaminating the imaging equipment that were used to image suspected or confirmed COVID-19 cases as well as the inaccessibility to that equipment for a period of time. Since COVID-19 patients are mostly exposed to a CT scan, the components of the scanner must be disinfected after contamination with alcohol containing disinfectants, and the room must be closed for an hour post decontamination as this will allow the process of air circulation and ventilation to take place. It is also advisable to train all radiology staff including the cleaning staff on the disinfecting process of all equipment including the imaging rooms and corridors. Moreover, some studies suggested that dividing radiographers into teams would help in reducing the risk of cross-infection and enhance safety within the Radiology Department. In addition, imaging the patients within the Emergency Department using Mobile Radiography would help in minimizing patient transfer $[1,8]$.

Furthermore, all radiology staff should not treat any patients without the use of Personal Protective Equipment (PPE) and as suggested by the European Centre for Disease Prevention and Control (2020); it should consist of a protective eye wear, surgical mask or disposable respirator, gloves and a long sleeved gown. Healthcare providers are recommended to provide any suspected infected patient with a surgical mask and to be directed to an isolation room for further consultation [9].

The reported death rates of health professionals were higher than other workers. It was noticed that the number of deaths has increased among them including radiographers [10].

According to the literature, training the radiology staff is crucial during this pandemic time. This will help to understand and follow the guidelines to reduce the viral transmission risk. Many strategies have been suggested to support the training such as Teleconferencing [11,12].

Accordingly, to prevent the spread of the COVID-19 disease in the UAE, it is important to evaluate the radiology staff awareness and attitude towards COVID-19 at this critical duration. In this study, the level of the awareness and compliance of COVID-19 im- 
aging and guidelines of the radiology staff will be assessed in different Emirates.

\section{Methods}

This survey study was approved by the research ethical committee of the institution to be conducted among the radiology staff inside the UAE. Radiographers and Radiologists are the eligible subjects to participate. In this study, a questionnaire was utilized and developed based on the published information regarding COVID-19 imaging and guidelines obtained from the world Health organization (WHO) website and relevant literature [1,19]. The questionnaire was made available online and sent to the participants to be filled and submitted electronically. The questionnaire (Appendix A) was divided in to 5 sections. The first section is the consent form to explain the research purpose to proceed and complete the questionnaire. The second section is about the demographic information such as gender, age and work experience. The third section includes multiple-choice questions (MCQs) regarding the knowledge and awareness level of COVID-19 disease such as symptoms and diagnostic tests. The fourth section measures compliance and frequency of applying COVID-19 infection control guidelines and safety procedures (Likert scale 1-5). The last section contains questions about the diagnostic role of the imaging modalities for COVID-19 cases.

For statistical analysis, ANOVA and Student's t test were used to compare the significant difference between the groups at a significance level of 0.05. Categorical variable such as gender, job and degree were expressed as proportions. For the Likert scale, the Mode of the responses (Never-Always:1-5) was used to express the most frequent response. Pearson's correlation coefficient test was used to test the correlation between the variables. Finally, the linear regression was used to find the significant predictors of the awareness level. The analysis was performed using SPSS (Statistical package for the social sciences) software.

Results

\section{Demographic information}

A total of 262 participants completed the questionnaires. The percentage of the females (48\%) was less than the males (52\%). The age of the participants ranged from 21 to 66 with a mean value of 36. Regarding the participant location, $58 \%$ of the participants were from the capital city (Abu Dhabi) while $42 \%$ were located outside the capital. Among them, $91 \%$ radiographers and $9 \%$ were radiologists. Bachelor degree was reported as $70 \%$ while $17 \%$ and $12 \%$ were reported for the Diploma and the Master degree respectively. $80 \%$ from the respondents work for the public sector while $20 \%$ are from non-public sector. Most of the participants (93\%) received information regarding the COVID-19 awareness.

\section{Mean scores of COVID-19 awareness and imaging sections}

The male participants scored higher than the females in both COVID-19 and COVID-19 Imaging awareness sections. There was no significant difference for both sections $(\mathrm{P}>0.05)$. According to the job title of the participants, both radiologists and radiographers scored similar results (70\%) for the COVID-19 awareness section without significant difference ( $\mathrm{P}>0.05$ ). On the other hand, radiologists scored higher than the radiographers for the COVID-19 imaging section $(\mathrm{P}<0.05)$. The Non-public sector participants scored higher than the public participants. However, there was no significant difference for both sections ( $\mathrm{P}>0.05$ ). For the COVID-19 imaging section, residents outside the capital and inside the capital scored similar results without significant difference $(P>0.05)$ but for the COVID-19 awareness section, residents outside the capital section scored higher than the capital $(\mathrm{P}<0.05)$. The results are summarized in table 1.

\begin{tabular}{|c|c|c|c|c|c|c|c|c|c|c|c|}
\hline & Job title & $\mathbf{N}$ & Mean & $\begin{array}{c}\text { Std. } \\
\text { Deviation }\end{array}$ & $\begin{array}{c}P \\
\text { value }\end{array}$ & & Sector type & $\mathbf{N}$ & Mean & $\begin{array}{c}\text { Std. } \\
\text { Deviation }\end{array}$ & $\begin{array}{c}P \\
\text { value }\end{array}$ \\
\hline \multirow[t]{2}{*}{$\begin{array}{c}\text { COVID-19 } \\
\text { Awareness } \\
\text { score }\end{array}$} & Radiologist & 23 & 0.65 & 0.18 & 0.43 & $\begin{array}{c}\text { COVID-19 } \\
\text { Awareness } \\
\text { score }\end{array}$ & Non-Public & 53 & 0.72 & 0.21 & 0.15 \\
\hline & Radiographer & 239 & 0.69 & 0.19 & & & Public & 209 & 0.68 & 0.19 & \\
\hline \multirow[t]{3}{*}{$\begin{array}{c}\text { COVID-19 } \\
\text { Imaging score }\end{array}$} & Radiologist & 23 & 0.62 & 0.13 & 0.02 & $\begin{array}{l}\text { COVID-19 } \\
\text { Imaging } \\
\text { score }\end{array}$ & Non-Public & 53 & 0.57 & 0.19 & 0.17 \\
\hline & Radiographer & 239 & 0.53 & 0.18 & & & Public & 209 & 0.54 & 0.18 & \\
\hline & Address/Location & $\mathbf{N}$ & Mean & $\begin{array}{c}\text { Std. } \\
\text { Deviation }\end{array}$ & $\begin{array}{c}P \\
\text { value }\end{array}$ & & Gender & $\mathbf{N}$ & Mean & $\begin{array}{c}\text { Std. } \\
\text { Deviation }\end{array}$ & $\begin{array}{c}P \\
\text { value }\end{array}$ \\
\hline \multirow{2}{*}{$\begin{array}{l}\text { COVID-19 } \\
\text { Awareness } \\
\text { score }\end{array}$} & Outside Capital & 151 & 0.66 & 0.17 & 0.00 & \multirow{2}{*}{$\begin{array}{c}\text { COVID-19 } \\
\text { Awareness } \\
\text { score }\end{array}$} & Female & 125 & 0.67 & 0.19 & 0.13 \\
\hline & Abu Dhabi Capital & 111 & 0.74 & 0.21 & & & Male & 137 & 0.71 & 0.20 & \\
\hline \multirow{2}{*}{$\begin{array}{l}\text { COVID-19 Im- } \\
\text { aging score }\end{array}$} & Outside Capital & 151 & 0.55 & 0.15 & 0.36 & \multirow{2}{*}{$\begin{array}{l}\text { COVID-19 } \\
\text { Imaging } \\
\text { score }\end{array}$} & Female & 125 & 0.53 & 0.20 & 0.29 \\
\hline & Abu Dhabi Capital & 111 & 0.53 & 0.22 & & & Male & 137 & 0.55 & 0.16 & \\
\hline
\end{tabular}

Table 1: Mean Scores of COVID-19 Awareness and Imaging Sections. 
According to the study level of the participants, the master level scored higher than the other degrees in both sections while Diploma level scored the lowest as shown in table 2. There was as no significant difference for both sections $(\mathrm{P}>0.05)$.

\begin{tabular}{|c|c|c|c|c|c|}
\hline & N & Mean & $\begin{array}{c}\text { Std. } \\
\text { Deviation }\end{array}$ & $\begin{array}{c}\text { P } \\
\text { value }\end{array}$ \\
\hline $\begin{array}{c}\text { COVID-19 } \\
\text { Awareness } \\
\text { score }\end{array}$ & Diploma & 44 & 0.68 & 0.18 & 0.52 \\
\hline & Bachelor & 187 & 0.69 & 0.19 & \\
\hline & Master & 31 & 0.73 & 0.21 & \\
\hline $\begin{array}{c}\text { COVID-19 Im- } \\
\text { aging score }\end{array}$ & Diploma & 44 & 0.50 & 0.17 & 0.22 \\
\hline & Bachelor & 187 & 0.55 & 0.18 & \\
\hline & Master & 31 & 0.57 & 0.17 & \\
\hline
\end{tabular}

Table 2: Study level Mean Scores of COVID-19 Awareness and Imaging Sections.

Correlation between work experience and awareness level

Using Pearson's correlation test, there was a significant correlation between the work experience and the awareness level $(r=0.3$, $\mathrm{P}<0.05)$. Additionally, the mean scores of both awareness sections were significantly correlated $(\mathrm{r}=0.15, \mathrm{P}<0.05)$.

\section{Compliance with COVID-19 infection control guidelines}

The factors that can control and reduce the transmission of the virus between staff and patients are summarized in table 3 . The Mode indicates the most chosen frequent action among participants ( 1 for lowest and 5 for the highest). Most of the participants have indicated that they (always) wear the protective mask and the protective apron, and disinfect the CT scanner after usage. On the other hand, most of the participants wear the protective goggles and ventilate the CT room less frequent (sometimes).

\section{Imaging working area}

Most of the participants (16\%) indicated that they work in general X-ray imaging followed by the MRI imaging (8\%) and the lowest percent was for NM imaging and the Cath lab as shown in figure 1.

\begin{tabular}{|c|c|c|c|c|c|}
\hline Questions & $\begin{array}{c}\text { How often do you } \\
\text { wear a protective } \\
\text { face mask? }\end{array}$ & $\begin{array}{c}\text { How often do you } \\
\text { wear a protective } \\
\text { googles? }\end{array}$ & $\begin{array}{c}\text { How often do you } \\
\text { wear a protective } \\
\text { apron? }\end{array}$ & $\begin{array}{c}\text { How often do you } \\
\text { disinfect the CT scanner } \\
\text { after being used? }\end{array}$ & $\begin{array}{c}\text { How often do you } \\
\text { ventilate CT room after } \\
\text { being used? }\end{array}$ \\
\hline N & 262 & 262 & 262 & 262 & 262 \\
\hline Mode & 5 & 3 & 5 & 5 & 3 \\
\hline Minimum & 2 & 1 & 1 & 1 & 1 \\
\hline Maximum & 5 & 5 & 5 & 5 & 5 \\
\hline
\end{tabular}

Table 3: Compliance with COVID-19 Infection Control guidelines.

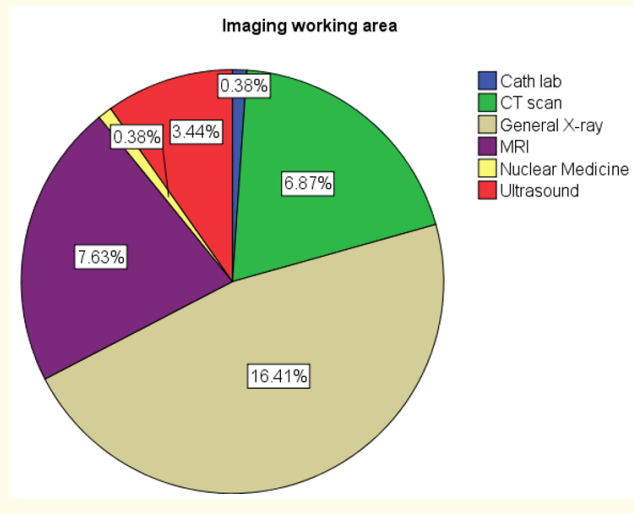

Figure 1: Imaging Working Areas.

\section{Overall COVID-19 imaging awareness scores}

Most of the participants (40\%) have the mean score for COVID-19 imaging section of $60 \%$ as shown in figure 2 .

\section{Prediction factors}

Using the linear regression test, COVID-19 imaging score section can be significantly predicted by the job title $(\mathrm{p}<0.05)$. On the other hand, COVID-19 score section can be significantly predicted by the work experience and the address factors $(p<0.05)$. The data are summarized in table 4 .

\section{Discussion}

This study was conducted in the UAE to evaluate the compliance and the awareness level of COVID-19 imaging and guidelines 


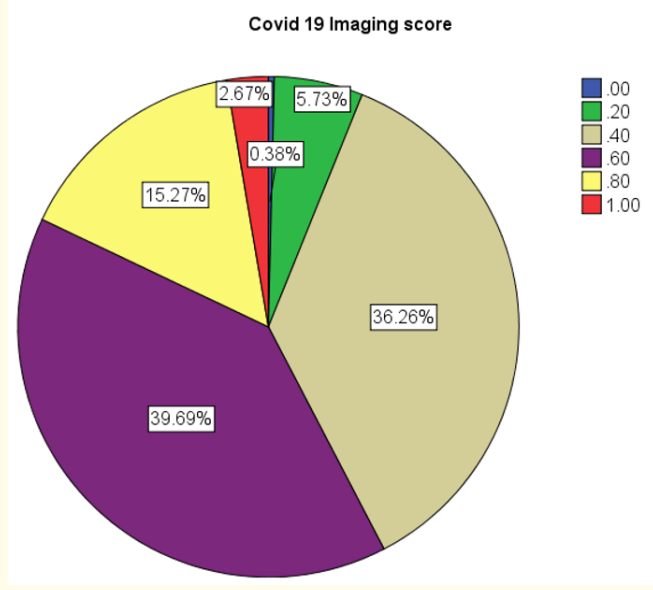

Figure 2: COVID-19 Imaging Awareness Scores.

\begin{tabular}{|c|c|c|c|}
\hline \multicolumn{2}{|c|}{$\begin{array}{c}\text { Dependent factor: C0- } \\
\text { VID-19 Imaging score }\end{array}$} & \multicolumn{2}{|c|}{$\begin{array}{c}\text { Dependent factor: COVID-19 } \\
\text { Awareness score }\end{array}$} \\
\hline Factors & $\begin{array}{c}\text { P } \\
\text { value }\end{array}$ & Factors & $\begin{array}{c}\text { P } \\
\text { value }\end{array}$ \\
\hline Gender & 0.77 & Gender & 0.14 \\
\hline Study level & 0.25 & Study level & 0.68 \\
\hline Job title & 0.03 & Job title & 0.74 \\
\hline Sector type & 0.20 & Sector type & 0.15 \\
\hline Address/Location & 0.48 & Address/ Location & 0.00 \\
\hline Work experience & 0.01 & Work experience (years) & 0.00 \\
\cline { 2 - 4 } (years) & & $\begin{array}{c}\text { Have you ever been } \\
\text { provided with COVID-19 } \\
\text { awareness session or train- } \\
\text { ing in any CovID-19 safety }\end{array}$ & 0.18 \\
procedures? & \\
\hline
\end{tabular}

Table 4: Prediction Factors.

among radiology staff. Participants from public and non-public sectors were included. To comply with COVID-19 safety measures and to reduce the viral transmission, the results were collected using online survey and administrated through different social media platforms and emails. The questionnaire emphasized on COVID-19 knowledge and awareness, Infection control and the role of imaging for COVID19 diagnosis.
A total of 262 participants accepted to participate in this study, which included 137 male staff members and 125 female staff members. Incomplete or irrelevant responses were excluded. Regarding the awareness level of COVID-19 and the role of imaging sections, there was no significant difference among the hospitals as similar guidelines were provided to all hospitals across UAE by the Ministry of Health and Prevention [13]. However, participants from Abu Dhabi have shown to have higher level of COVID-19 awareness than participants from regions outside Abu Dhabi. This indicates that the capital city has conducted more awareness sessions regarding the pandemic.

Among the respondents, 91\% of the participants were radiographers while $9 \%$ were radiologists. Due to the increased number of COVID-19 patients and the imaging workload especially on CT and $\mathrm{x}$-ray, it was reported that more radiographers we requested to overcome the increased demand [14].

Similar scores (70\%) of COVID-19 awareness were found between the radiographers and radiologists, as they were provided with similar COVID-19 guidelines sessions, though the score of COVID-19 imaging awareness was significantly higher among the radiologists with $62 \%$. This can be due to the job competencies where imaging reports usually written and interpreted by the radiologists, while radiographers mainly conduct the imaging procedure [5].

Regarding the academic degrees, participants with the master degree scored higher than the other degrees. This is similar to a study showed that COVID-19 knowledge score was significantly higher for master degree holders [15].

The Correlation test showed significant association between the awareness level and the work experience. Similar results were observed in another cross sectional study was used to evaluate the COVID-19 awareness [16].

The overall guidelines for COVID-19 awareness from the government were efficiently delivered to all the hospitals across the country as specified in the result section with a high score of $70 \%$. Similar results were found in the cross sectional study conducted among various Arab world countries [16]. The hospitals have also shown a higher compliance with COVID-19 infection control guidelines by wearing protective apron and mask and disinfecting 
the CT scanner after the usage. This is consistent with the recommended protection guidelines to reduce the risk of the infection $[5,17,18]$.

Most of the respondents reported that they work in the general $\mathrm{x}$-ray area (16\%) while the least percentage was found in the Cath lab $(0.4 \%)$. This can be linked to the increased $x$-ray imaging workload in comparison to other imaging modalities.

Overall, the mean score of the COVID-19 awareness was higher (70\%) in comparison to the mean score of COVID-19 imaging awareness (60\%). This requires more imaging awareness sessions to be provided to the radiology staff.

To our knowledge, this is the first type of study to be conducted among radiology staff across the UAE. This can provide a baseline for future related studies. However, a larger sample size was expected to be included but due to the current pandemic, it was difficult to contact the staff in person to reach out more participants. Nevertheless, the current study provided an insight into the current level of awareness and compliance among the radiology staff of different Emirates in the UAE, and more attention is needed for the COVID-19 imaging awareness.

\section{Conclusions}

The findings of this study indicate that the radiology staff in the UAE healthcare facilities have an acceptable knowledge and appropriate practices towards COVID-19 imaging during the period of COVID-19 outbreak. The results reflect the efforts of UAE health authorities in increasing the awareness level. More imaging awareness sessions are recommended to improve the overall performance.

\section{Acknowledgments}

The authors would like to thank the Radiography and Medical Imaging senior students (Afraa Yaslam Ali Al Akbari, Fatima Ali Afef Ali Amer AlYafei, Hasina Umra Khan, Mariam Mohamed AL Tamimi) for providing help during the research.

\section{Funding}

This study did not receive any specific grant from funding agencies in the public, commercial, or not-for-profit sectors.

\section{Competing Interests}

All authors have completed the ICMJE uniform disclosure form at www.icmje.org/coi_disclosure.pdf and declare: no financial relationships with any organizations that might have an interest in the submitted work in the previous three years; no other relationships or activities that could appear to have influenced the submitted work.

\section{Ethical Approval}

Informed consent was obtained from all participants. The Research ethical committee of the institution approved the study.

\section{Conflict of Interest Statement}

None.

\section{Bibliography}

1. Stogiannos N., et al. "COVID-19 in the radiology department: What radiographers need to know". Radiography 26.3 (2020): 254-263.

2. Kooraki S., et al. "Coronavirus (COVID-19) Outbreak: What the Department of Radiology Should Know". Journal of the American College of Radiology 17.4 (2020): 447-451.

3. Kotian RP., et al. "Knowledge and understanding among medical imaging professionals in India during the rapid rise of the covid-19 pandemic". Health Technology (Berl). (2020): 1-6.

4. Redmond CE., et al. "Emergency Radiology During the COVID-19 Pandemic: The Canadian Association of Radiologists Recommendations for Practice". Canadian Association of Radiologists Journal 71.4 (2020): 425-430.

5. Qu J., et al. "Infection Control for CT Equipment and Radiographers' Personal Protection During the Coronavirus Disease (COVID-19) Outbreak in China". American Journal of Roentgenology 215.4 (2020): 940-944.

6. Kooraki S., et al. "Coronavirus Disease 2019 (COVID-19) Precautions: What the MRI Suite Should Know". Journal of the American College of Radiology 17.7 (2020): 830.

7. Langenbach MC., et al. "MRI appearance of COVID-19 infection". Diagnostic and Interventional Radiology 26.4 (2020): 377-378. 
8. Devaraj A. "Important lessons for infection control in radiology departments during the COVID-19 pandemic". European Radiology 30.7 (2020): 3599.

9. Guidance for wearing and removing personal protective equipment in healthcare settings for the care of patients with suspected or confirmed COVID-19 (2020).

10. Radiographer and former Society rep dies from Covid-19 (2020).

11. Alvin MD., et al. "The Impact of COVID-19 on Radiology Trainees". Radiology 296.2 (2020): 246-248.

12. Yan C., et al. "Recommendations for coronavirus disease 2019 (COVID-19) prevention and infection control in the radiology department: Chinese experience". Clinical Imaging 69 (2021): 33-36.

13. Ministry of Health and Prevention - UAE (2020).

14. Akudjedu TN., et al. "Impact of the COVID-19 pandemic on radiography practice: findings from a UK radiography workforce survey". BJR/Open 2.1 (2020): 20200023.

15. Hua F., et al. "COVID-19 Related Experience, Knowledge, Attitude, and Behaviors Among 2,669 Orthodontists, Orthodontic Residents, and Nurses in China: A Cross-Sectional Survey". Frontiers in Medicine 7 (2020): 481.

16. Bonyan R., et al. "Identification of the awareness level by the public of Arab countries toward COVID-19: Cross-sectional study following an outbreak". Journal of Pharmaceutical Policy and Practice 13 (2020): 43.

17. Lahoti A and Makasare K. "Corona virus outbreak and Radiology Department: Workplace preparedness, evidence based measures to limit transmission, and how radiologist can help reduce the spread". Journal of Dr. NTR University of Health Sciences 9.2 (2020): 67-73.

18. Zanardo M., et al. "Management of patients with suspected or confirmed COVID-19, in the radiology department". Radiography 26.3 (2020): 264-268.

19. Coronavirus disease (COVID-19) pandemic (2020).

Volume 4 Issue 10 October 2021

(C) All rights are reserved by Mohamed Hasaneen and

Mustafa Alhasan. 